\title{
Non-utilization of health facility delivery and its correlates among childbearing women: a cross-sectional analysis of the 2018 Guinea demographic and health survey data
}

\author{
Bright Opoku AhinkorahiD
}

\begin{abstract}
Background: Many childbearing women in sub-Saharan African countries like Guinea still face challenges accessing and utilizing health facility delivery services and opt to deliver at home. This study examined the non-utilization of health facility delivery and its associated factors among childbearing women in Guinea.

Methods: Data from the 2018 Guinea Demographic and Health Survey was used in this study. Data of 5406 childbearing women were analysed using STATA version 14.2 by employing a multilevel logistic regression approach. The results were presented using adjusted odds ratios (aOR) at 95\% confidence interval (CI).

Results: More than three-quarters (47.6\%) of childbearing women in Guinea did not deliver at health facilities. Women who had no formal education ( $\mathrm{aOR}=1.52,95 \% \mathrm{Cl}=1.09-2.12)$, those whose partners had no formal education $(\mathrm{aOR}=1.25,95 \% \mathrm{Cl}=1.01-1.56)$, those whose pregnancies were unintended $(\mathrm{aOR}=1.40,95 \% \mathrm{Cl}=1.13-1.74)$ and those who were Muslims ( $\mathrm{aOR}=2.87,95 \% \mathrm{Cl}=1.17-7.08)$ were more likely to deliver at home. Furthermore, women with parity four or more $(a \mathrm{OR}=1.78,95 \% \mathrm{Cl}=1.34-2.37)$, those who listened to radio less than once a week $(\mathrm{aOR}=5.05$, $95 \% \mathrm{Cl}=1.83-13.89$ ), those who never watched television ( $\mathrm{aOR}=1.46,95 \% \mathrm{Cl}=1.12-1.91)$, those with poorest wealth quintile ( $\mathrm{aOR}=4.29,95 \% \mathrm{Cl}=2.79-6.60)$, women in female-headed households ( $\mathrm{aOR}=1.38,95 \% \mathrm{Cl}=1.08-1.78$ ) and rural dwellers ( $\mathrm{aOR}=3.86,95 \% \mathrm{Cl}=2.66-5.60$ ) were more likely to deliver at home.
\end{abstract}

Conclusion: This study has identified low socio-economic status, inadequate exposure to media, having an unplanned pregnancy and religious disparities as key predictors of home delivery among childbearing women in Guinea. The findings call for the need to enhance advocacy and educational strategies like focus group discussions, peer teaching, mentor-mentee programmes at both national and community levels for women to encourage health facility delivery. There is also the need to improve maternal healthcare services utilization policies to promote access to health facility delivery by reducing costs and making health facilities available in communities.

Keywords: Home delivery, Childbearing women, Guinea, Community health, Global Health

Correspondence: brightahinkorah@gmail.com

School of Public Health, Faculty of Health, University of Technology Sydney,

Sydney, New South Wales, Australia

(c) The Author(s). 2020 Open Access This article is licensed under a Creative Commons Attribution 4.0 International License, which permits use, sharing, adaptation, distribution and reproduction in any medium or format, as long as you give appropriate credit to the original author(s) and the source, provide a link to the Creative Commons licence, and indicate if changes were made. The images or other third party material in this article are included in the article's Creative Commons licence, unless indicated otherwise in a credit line to the material. If material is not included in the article's Creative Commons licence and your intended use is not permitted by statutory regulation or exceeds the permitted use, you will need to obtain permission directly from the copyright holder. To view a copy of this licence, visit http://creativecommons.org/licenses/by/4.0/ The Creative Commons Public Domain Dedication waiver (http://creativecommons.org/publicdomain/zero/1.0/) applies to the data made available in this article, unless otherwise stated in a credit line to the data. 


\section{Background}

Maternal mortality continues to be a key public health issue of great concern globally [1-3]. Globally, maternal mortality ratio as at 2019 stood at 211 per 100,000 live births [3]. Health facility deliveries have been found to be associated with reduction in maternal and newborn deaths $[4,5]$. One of the key strategies recommended by the World Health Organization (WHO) in its attempt to reduce maternal and infant death is the accessibility of health facilities with skilled birth attendants who can deal with emergency obstetric cases [6].

In sub-Saharan Africa (SSA), the current maternal mortality ratio is 534 per 100,000 live births, which is higher than the average ratio globally (211 per 100,000 live births) [3]. Despite significant efforts to reduce maternal deaths through enhanced maternal healthcare services utilization globally [7-9], many childbearing women in SSA still face challenges accessing and utilizing maternal healthcare services, including delivery services and opt to deliver at home [10,11].

Evidence suggests that home births pose high risks to the health of the mother and the child during the period after delivery $[12,13]$. Some of these risks include desertion of colostrum provision and breastfeeding practices. Other risks include neglect of immunisations and nutrition supplementation for mother and child and lack of postnatal care check-up for the child and mother [14-16].

As part of efforts to enhance health facility delivery and reduce maternal and child mortality in Guinea, the Government introduced the Maternal Deaths Surveillance and Response (MDSR) which focused on carrying out routine exercises to identify, notify, quantify, and determine the causes of maternal deaths and how they can be avoided as well as providing education on the use of maternal healthcare services to mothers. This initiative was enhanced by setting up an online approach called "District.Team" in 2016, to facilitate horizontal learning between health district management teams (HDMTs) [17].

Despite all these efforts, Guinea continues to be one of the countries in SSA with high maternal mortality ratio as the country recorded 747 maternal deaths per 100, 000 live births in 2010, then 699 per 100,000 live births in 2015 and 576 per 100,000 live births in 2017 [18]. The high maternal mortality ratio in Guinea has been attributed to the high home births due to several sociocultural factors including having high trust and comfort in local birth attendants and community midwives, distance to health facilities, and inadequate financial resources to cater for transportation cost and other costs that are not catered for during delivery [19]. This to some extent has also contributed to the high under-five mortality recorded in the country. For instance, in 2018, child mortality rate for Guinea was 101.1 deaths per 1000 live births [20].

Apart from these socio-cultural factors, studies conducted in different sub-Saharan African countries such as Nigeria [21, 22], Guinea-Bissau [23], Zambia [24], Tanzania [25], Kenya [26] and Ghana [27] have found individual and contextual level factors such as maternal age, maternal level of education, marital status, place of residence, exposure to media, religion, parity, wealth status and women's decision making capacity as predictors of home delivery.

Despite the high rate of home delivery with its associated maternal and child mortality in Guinea, there has not been any study that has examined the factors associated with the non-utilization of health facility delivery in the country. This study, therefore, examined the factors associated with the non-utilization of health facility delivery among childbearing women in Guinea using data from the 2018 Guinea Demographic and Health Survey. Findings from the study are important to Guinea as they can form the basis for improved health facility delivery services utilization, which can help reduce maternal and child mortality in the country.

\section{Methods \\ Study area}

The area for the study was Guinea. The Republic of Guinea is located in West Africa and is one of the world's poorest countries, ranked 178th out of 187 countries on the 2011 Human Development Index [28]. Based on the 2019 population of 12.77 million people, Guinea's population density is 134.5 people per square mile (51.9 people per square kilometer), which ranks 127th in the world [29]. According to the Integrated Core Survey for the Evaluation of Poverty (EIBEP 2002-2003), access to healthcare services in the country (under $30 \mathrm{~min}$ ) was $38.9 \%$ and utilization of healthcare services was 18.6\% [30].

\section{Study design and data source}

A cross-sectional study design using data from the women's file of the 2018 Guinea Demographic and Health Survey (GDHS) was considered in this study. GDHS is part of a number of surveys obtained from the MEASURE DHS Program and contains information on a number of population and health issues including place of delivery. In sampling respondents for the GDHS, a two-stage stratified sampling approach was employed. The first stage involved the selection of clusters usually called enumeration areas (EAs) and the second stage consisted of the selection of households for the survey. The average size of EAs was 186 household in urban areas and 140 households in rural areas, with an average of 153 households. Out of these households, 10,874 
women were interviewed [31]. In this study, data of 5406 women aged 15-49 with at least one child ever born were analysed. Detailed information about the methods used in the survey can be found in the final report [31].

\section{Study variables}

\section{Outcome variable}

Place of delivery was the outcome variable in this study. This was grouped into home and health facility delivery. Home delivery was described as any birth that took place in the women's home or others' home whereas health facility delivery referred to deliveries that took place in governmental health posts, health centers, hospitals, private clinics and maternity homes [31].

\section{Explanatory variables}

Fifteen explanatory variables, made up of 11 individual level factors (age, mother's education level, partner's educational level, pregnancy intention, religion, marital status, parity, employment status, frequency of reading newspaper, frequency of listening to radio, frequency of watching television) and four contextual factors (wealth quintile, place of residence, decision making in healthcare, and sex of household head) were considered for this study. Age was coded as 15-24, 25-34, and 35+. Mother and partner's level of education were categorised into no education, primary and secondary/higher. Parity was coded as one birth, two births, three births and four or more births. Employment status was coded as working and not working. Not at all, less than once a week and at least once a week were used as codes for frequency of reading newspaper, listening to radio, and watching television. Wealth quintile was coded as poorest, poorer, middle, richer and richest. Place of residence was coded as rural and urban. Healthcare decision making was coded as alone and not alone and male and female were used as description for sex of household head. These variables were chosen due to their significant associations with non-utilization of health facility delivery in previous studies in SSA [12, 32-34].

\section{Statistical analyses}

Analyses were carried out using a two-step analytical approach with the help of STATA version 14.2 for windows. First, the prevalence of non-utilization of health facility delivery and its distribution across the individual and contextual factors were presented. Statistical significance of the association between each of the factors and non-use of health facility delivery was measured using Pearson's' chi-square $\left[\mathrm{x}^{2}\right]$ at a $p<0.05$ (see Table 1). This was followed by a two-level multilevel multivariable logistic regression analysis carried out to examine the individual and contextual factors associated with nonutilization of health facility delivery. Four models were fitted (Model 0, 1, 2 and 3) using the STATA command "melogit". Models were compared using the loglikelihood ratio (LLR) and Akaike's Information Criterion (AIC) tests and the model with the highest log-likelihood and the lowest AIC was regarded as the best fit model (see Table 2). Adjusted odds ratios (aOR) were presented for all the models apart from model 0 at 95\% confidence intervals (CIs) (see Table 2). Multicollinearity test was done using the variance inflation factor (VIF) and no evidence of high collinearity was found. All frequency distributions were weighted. The manuscript was written by following the Strengthening Reporting of Observational studies in Epidemiology (STROBE) reporting guidelines [35].

\section{Ethical approval}

This study made use of secondary data from DHS. Hence, no additional ethical approval was required as the data is freely available to the general public. However, the author sought permission from MEASURE DHS to use the data for this study. Details of the ethical standards are available on http://goo.gl/ny8T6X.

\section{Results \\ Distribution of non-utilization of health facility delivery by socio-demographic characteristics of childbearing women in Guinea}

Table 1 presents the results on the distribution of nonutilization of health facility delivery by sociodemographic characteristics of childbearing women in Guinea. Overall, $47.6 \%$ of childbearing women in Guinea delivered at home. It was found that $53.6 \%$ of the childbearing aged 35 years and above delivered at home, $55.7 \%$ of those who had no formal education and $56.4 \%$ of those whose partners had no formal education delivered at home. Home delivery was found to be high among Muslim women (51.9\%), those who had unintended pregnancies (56.9\%), married women (49.9\%), women with four or more births (55.1\%) and working women $(50.3 \%)$. The majority of women who never read newspaper (55.4\%), listened to radio (55.8\%), watched television (62.1\%), those with poorest wealth quintile (76.7\%), those in male-headed households (50.7\%), those who did not make healthcare decisions alone (50.1\%) and those who lived in rural areas (62.1\%) had high prevalence of home delivery. The chi-square analysis results also showed that all the independent variables, apart from employment status, showed statistically significant associations with home delivery $(p<0.05)$.

\section{Predictors of non-utilization of health facility delivery among childbearing women in Guinea}

Table 2 shows the fixed and random effects results on the predictors of non-utilization of health facility 
Table 1 Distribution of non-utilization of health facility delivery by socio-demographic characteristics of childbearing women in Guinea (Weighted $N=5406$ )

\begin{tabular}{llll}
\hline Variables & Frequency (N) & Percentage (\%) & Hom \\
\hline Age & & & 46.5 \\
$15-24$ & 1362 & 27.0 & 48.9 \\
$25-34$ & 2308 & 45.7 & 53.6 \\
$35+$ & 1376 & 27.3 & \\
Mother's level of education & & & 78.2 \\
$\quad$ No education & 3945 & 10.5 & 15.8 \\
$\quad$ Primary & 531 & 11.3 & \\
$\quad$ Secondary/Higher & 570 & &
\end{tabular}

$\begin{array}{llll}\text { No education } & 3690 & 73.1 & 56.4 \\ \text { Primary } & 357 & 7.1 & 42.8 \\ \text { Secondary/Higher } & 999 & 19.8 & 25.7\end{array}$

\begin{tabular}{ll} 
Home delivery (47.6\%) & $p$-value \\
\hline 6.5 & $p=0.001$ \\
8.9 & \\
3.6 &
\end{tabular}

$p<0.001$

55.7

39.9

15.8

56.4

42.8

25.7

Religion

Christianity

516

10.2

$p<0.001$

Islam

4447

Others

83

88.1

28.0

51.9

Pregnancy intention

1.6

$$
p<0.001
$$

Unintended

Planned

719

Marital status

Married

Cohabiting

Parity

One birth

Two births

Three births

Four or more births

\section{Employment status}

Not working

Working

Frequency of reading newspaper

Not at all

Less than once a week

At least once a week

Frequency of listening to radio

Not at all

Less than once a week

At least once a week

Frequency of watching television

Not at all
Less than once a week

At least once a week

\section{Wealth quintile}

4327

\section{2}

85.8

4944

102

98.0

2.0

15.6

18.1

18.9

47.5

2395

1252

3793

4784

147

116

2084

1402

1560

3127

906

1013

\section{5}


Table 1 Distribution of non-utilization of health facility delivery by socio-demographic characteristics of childbearing women in Guinea (Weighted $N=5406$ ) (Continued)

\begin{tabular}{|c|c|c|c|c|}
\hline Variables & Frequency (N) & Percentage (\%) & Home delivery $(47.6 \%)$ & $p$-value \\
\hline Poorest & 1213 & 24.0 & 76.7 & \\
\hline Poorer & 1139 & 22.6 & 62.0 & \\
\hline Middle & 997 & 19.8 & 50.6 & \\
\hline Richer & 956 & 19.0 & 26.0 & \\
\hline Richest & 741 & 14.7 & 13.1 & \\
\hline Sex of household head & & & & $p<0.001$ \\
\hline Male & 4525 & 88.7 & 50.7 & \\
\hline Female & 521 & 10.3 & 39.6 & \\
\hline Health care decision making & & & & $p=0.016$ \\
\hline Alone & 514 & 10.2 & 44.2 & \\
\hline Not alone & 4532 & 89.8 & 50.1 & \\
\hline Place of residence & & & & $p<0.001$ \\
\hline Urban & 1407 & 27.9 & 17.2 & \\
\hline Rural & 3639 & 72.1 & 62.1 & \\
\hline
\end{tabular}

Source: 2018 Guinea Demographic and Health Survey

delivery among childbearing women in Guinea. In terms of the fixed effects results, it was found that women who had no formal education $(\mathrm{aOR}=1.52$, 95\% CI $=1.09$ 2.12 ), those whose partners had no formal education $(\mathrm{aOR}=1.25,95 \% \mathrm{CI}=1.01-1.56)$, those whose pregnancies were unintended $(\mathrm{aOR}=1.40,95 \% \mathrm{CI}=1.13-1.74$ ) and those who were Muslims $(\mathrm{aOR}=2.87,95 \% \mathrm{CI}=$ 1.17-7.08) had higher odds of delivery at home, compared to those who had secondary/higher education, those whose partners had secondary/higher education, those with planned pregnancies and those who belonged to other religions respectively. The results further showed that women with four or more births $(\mathrm{aOR}=1.78,95 \% \mathrm{CI}=1.34-2.37)$, those who listened to radio less than once a week $(\mathrm{aOR}=5.05,95 \% \mathrm{CI}=$ 1.83-13.89), those who never watched television $(\mathrm{aOR}=1.46,95 \% \mathrm{CI}=1.12-1.91)$, those with poorest wealth quintile $(\mathrm{aOR}=4.29,95 \% \mathrm{CI}=2.79-6.60)$, women in male-headed households $(\mathrm{aOR}=1.38,95 \%$ $\mathrm{CI}=1.08-1.78)$ and those who lived in rural areas $(\mathrm{aOR}=3.86,95 \% \mathrm{CI}=2.66-5.60)$ had higher odds of home delivery compared to those with one birth, those who read newspaper at least once a week, those who watched television at least once a week, those with richest wealth quintile, those in female-headed households and urban dwellers, respectively.

With the random effects results, the complete model (Model 3), which included all the individual and contextual level factors in the model and had an AIC of 5232.3 and a log-likelihood ratio of -2588.1 , was considered as the best fit model for predicting the occurrence of home delivery among childbearing women.

\section{Discussion}

This study sought to assess the predictors of nonutilization of health facility delivery among childbearing women in Guinea. The prevalence of home delivery among childbearing women in Guinea is relatively high, as compared to what has been found previously in other countries in SSA like Ethiopia-44\% [36] and Tanzania$21 \%$ [37]. Other studies, however, have identified high prevalence of home delivery, compared to this study. For instance, a study in Guinea found a prevalence of $61.8 \%$ home deliveries among women [38]. Other studies in Ghana [34], Nigeria [39] and Ethiopia [32], identified a prevalence of 59,62 and $67.2 \%$ of home deliveries among women respectively. The disparities in prevalence of home delivery in this study, compared to other previous studies could be due to differences in study population and samples. The relatively high prevalence of home delivery among childbearing women in Guinea could be related to the disparities in access to maternal healthcare services, including health facility delivery in Guinea, which became very predominant during the Ebola outbreak and from which the country is still recovering [40-42]. The relatively high utilization of home delivery has implication for maternal healthcare utilization and maternal and child healthcare in Guinea. This is because, as many more pregnant women deliver at home, the use of health facility delivery which has been found to improve the health status of women and children will be low and this can lead to an increase in child and maternal mortality in the country.

Low socio-economic status, manifested in lack of formal education for both woman and partner, poorest 
Table 2 Predictors of non-utilization of health facility delivery among childbearing women in Guinea

\begin{tabular}{l} 
Variables \\
\hline Age \\
$15-24$ \\
$25-34$ \\
$35+$
\end{tabular}

Model $0 \quad$ Model 1

aOR (Cl)

Mother's level of education

No education
Primary
Secondary/Higher

Partner's level of education

No education
Primary
Secondary/Higher

\section{Pregnancy intention}

Unintended

Planned

\section{Religion}

Christianity

Islam

Others

\section{Marital status}

Married

Cohabiting

\section{Parity}

One birth

Two births

Three births

Four or more births

\section{Frequency of reading newspaper}

Not at all

Less than once a week

At least once a week

\section{Frequency of listening to radio}

Not at all

Less than once a week

At least once a week

\section{Frequency of watching television}

Not at all

Less than once a week

At least once a week

\section{Wealth quintile}

Poorest

Poorer

Middle
Ref

$0.80(0.64-1.00)$

$0.76^{*}(0.58-0.99)$

$1.88^{* * *}(1.35-2.62)$

$1.39(0.96-2.01)$

Ref

$1.49^{* * *}(1.19-1.85)$

1.16 (0.83-1.62)

Ref

$1.36^{* *}(1.10-1.68)$

Ref

$0.72(0.28-1.83)$

$1.36(0.52-3.58)$

Ref

$1.08(0.58-2.01)$

Ref

Ref

$1.67^{* * *}(1.28-2.18)$

$1.60^{* * *}(1.21-2.13)$

$2.00^{* * *}(1.50-2.65)$

$5.26^{* * *}(2.15-12.88)$

$5.53^{* * *}(1.98-15.45)$

Ref

0.97 (0.79-1.19)

Ref

$1.10(0.90-1.35)$

$2.42^{* * *}(1.87-3.14)$

$1.48^{* * *}(1.13-3.14)$

Ref
Ref

$0.89(0.71-1.11)$

$0.86(0.65-1.12)$

$1.52^{*}(1.09-2.12)$

$1.28(0.89-1.86)$

Ref

$1.25^{*}(1.01-1.56)$

$1.05(0.75-1.46)$

Ref

$1.40^{* *}(1.13-1.74)$

Ref

$0.96(0.40-2.33)$

$2.87^{*}(1.17-7.08)$

Ref

$1.09(0.59-2.02)$

Ref

Ref

$1.59^{* * * *}(1.22-2.07)$

$1.51^{* *}(1.14-2.01)$

$1.78^{* * *}(1.34-2.37)$

$4.52^{* * *}(1.87-10.90)$

$5.05^{* *}(1.83-13.89)$

Ref

$0.99(0.81-1.21)$

Ref

$1.06(0.87-1.31)$

$1.46^{* *}(1.12-1.91)$

$1.12(0.85-1.49)$

Ref

$5.79^{* * *}(3.84-8.72)$
$3.72^{* * *}(2.50-5.54)$
$2.54^{* * *}(1.73-3.73)$
$4.29^{* * *}(2.79-6.60)$

$2.82^{* * *}(1.86-4.28)$

$1.93^{* *}(1.30-2.89)$ 
Table 2 Predictors of non-utilization of health facility delivery among childbearing women in Guinea (Continued)

\begin{tabular}{|c|c|c|c|c|}
\hline Variables & Model 0 & $\begin{array}{l}\text { Model } 1 \\
\text { aOR (CI) }\end{array}$ & $\begin{array}{l}\text { Model } 2 \\
\text { aOR (Cl) }\end{array}$ & $\begin{array}{l}\text { Model } 3 \\
\text { aOR (CI) }\end{array}$ \\
\hline Richer & & & $1.58^{* * *}(1.14-2.18)$ & $1.28(0.92-1.78)$ \\
\hline Richest & & & Ref & Ref \\
\hline \multicolumn{5}{|l|}{ Sex of household head } \\
\hline Male & & & $1.47^{* * *}(1.15-1.88)$ & $1.38^{*}(1.08-1.78)$ \\
\hline Female & & & Ref & Ref \\
\hline \multicolumn{5}{|c|}{ Health care decision making } \\
\hline Alone & & & Ref & Ref \\
\hline Not alone & & & $1.10(0.85-1.41)$ & $1.20(0.93-1.55)$ \\
\hline \multicolumn{5}{|l|}{ Place of residence } \\
\hline Urban & & & Ref & Ref \\
\hline Rural & & & $4.92^{* * *}(3.34-7.25)$ & $3.86^{* * *}(2.66-5.60)$ \\
\hline \multicolumn{5}{|l|}{ Random effects results } \\
\hline PSU Variance $(95 \% \mathrm{Cl})$ & $2.0(0.8-5.0)$ & $2.2(1.0-5.3)$ & $2.1(0.9-0.51)$ & $2.1(0.9-5.3)$ \\
\hline ICC & 0.51 & 0.39 & 0.30 & 0.25 \\
\hline LR Test & $\begin{array}{l}x^{2}=1394.0 \\
p<0.001\end{array}$ & $\begin{array}{l}x^{2}=608.8 \\
p<0.001\end{array}$ & $\begin{array}{l}x^{2}=477.68 \\
p<0.001\end{array}$ & $\begin{array}{l}x^{2}=299.3 \\
p<0.001\end{array}$ \\
\hline Wald $x^{2}$ & Reference & $182.3^{* * *}$ & $347.1^{* * *}$ & $476.7^{* * *}$ \\
\hline \multicolumn{5}{|l|}{ Model fitness } \\
\hline Log-likelihood & -2800.5 & -2699.6 & -2651.4 & -2588.1 \\
\hline AIC & 5604.9 & 5441.2 & 5320.8 & 5232.3 \\
\hline Sample size & 5406 & 5406 & 5406 & 5406 \\
\hline
\end{tabular}

Source: 2018 Guinea Demographic and Health Survey

Model 0 is the null model, a baseline model without any determinant variable

Model 1 is adjusted for individual-level variables

Model 2 is adjusted for contextual-level variables

Model 3 is the final model adjusted for individual and contextual-level variables

aOR Adjusted odds ratios

$\mathrm{Cl}$ Confidence interval

Ref Reference category

PSU Primary Sampling Unit

ICC Intra-Class Correlation

LR Test Likelihood ratio Test

AIC Akaike's Information Criterion

${ }^{*} p<0.05,{ }^{* *} p<0.01,{ }^{* * *} p<0.001$

wealth quintile and rural dwelling was linked with a higher likelihood of home delivery. Previous studies have also found factors such as lower wealth quintile [23, 34, $43,44]$, lack of education [45-48] and rural dwelling [44, $49,50]$ as predictors of home delivery. In most of these studies, the possible reasons provided for the increased likelihood of home delivery among these cohorts of pregnant women is financial and geographical barriers to accessing health facility deliveries. Other studies have also asserted that women who have no formal education, those whose partners have no formal education, those who are poor and live in rural areas may not have adequate knowledge about the risks associated with home delivery and hence may see no need to go and deliver at the health facility in the midst of their poor socioeconomic status $[12,51,52]$. Findings on the association between socio-economic status and home delivery implies that enhancing health facility delivery will depend on improving the socio-economic status of pregnant women. This can be done through the collaborative efforts of government and non-governmental organisations in Guinea by providing women with skilled training and educational opportunities that will give them the economic empowerment to access health facility delivery.

In this study, women who were less exposed to media (newspaper and television) were more likely to deliver at home. Other previous studies have also identified a link between media exposure and choice of place of delivery, with women who are not exposed to media more likely to deliver at home compared to those who have media exposure [12, 53-55]. The possible reason for the increase in home delivery among women who are not exposed to media is that exposure to mass media offers 
high awareness and knowledge about pregnancy and birth-related complications [55]. It also changes a woman's attitude, social norms and behavior that may lead to high access of health facility delivery [55]. The role of media in a pregnant woman's choice of place of delivery calls for enhancement in access to media. Community-based information systems in Guinea can be used as platforms to communicate health messages to women while at the same time ensuring that women obtain the needed information they need from newspaper and television.

Muslim women were more likely to deliver at home in this study, compared to women who belonged to other religions. Similar to the findings of this study, a study in Nepal, identified that Muslim women were more likely to deliver at home compared to women of other religions [33]. A study in Ghana also identified low utilization of maternal healthcare skilled service among Muslim women [56]. The author explained that most Muslim women deliver at home because of the religious obligation to ensure a sanctified body through modest dressing and the avoidance of unlawful bodily exposure to people including male caregivers [56]. Other reasons were barriers to maternal healthcare such as lack of privacy, inadequate knowledge of healthcare workers about Muslim women's religious and cultural practices and absence of cultural or religious-specific maternal healthcare services [56]. The high odds of home delivery among Muslim women could also be attributed to factors such as living in male-headed households and having four or more births, which were found to increase home deliveries and are sometimes considered as characteristics of Muslim women [57-59]. The findings on the association between religion and home delivery calls for the need for maternal healthcare services utilization strategies to pay more attention to Muslim women by exploring their religious norms and practices and understanding how they play a role in their choice of place of delivery.

Although unintended pregnancy has been considered to be associated with pregnancy-related complications such as poor weight gain, pregnancy-induced hypertension and anemia $[60,61]$, which warrants the need for health facility delivery, women with unintended pregnancies in this study had higher odds of delivering at home compared to those whose pregnancies were planned. This corroborates the findings of previous studies $[62,63]$. The plausible reason for this finding can be understood in the context of age and unintended pregnancy, where studies have found high prevalence of unintended pregnancies among younger women [6466]. Within this context, the high rate of home delivery attributed to unintended pregnancies could be explained in line with existing socio-cultural barriers and stigma which can hinder access to maternal healthcare services including health facility delivery [67-69]. The findings show the importance of encouraging pregnant women with unintended pregnancies to access health facility delivery by making them understand the implications of home delivery related to unintended pregnancies.

One key limitation of this study emanates from the design employed-cross sectional-which does not give room for causal inference to be made about its emergent results. Another limitation of the study is the difference in periods of data collection for the outcome variable "place of delivery" and the explanatory variables. Whiles data on the outcome variable asked questions on a phenomenon that occurred in the past, data on explanatory variables related to what was happening at the time of data collection, which may affect the findings and interpretations. In spite of these, the study presents current evidence on drivers of home delivery among childbearing women in Guinea using data from a nationally-representative survey.

\section{Conclusion}

This study has identified factors such as low socioeconomic status, low exposure to media, having an unplanned pregnancy and religious disparities as key predictors of non-utilization of health facility delivery among childbearing women in Guinea. The importance of enhancing health facility delivery and reducing if not eliminating home delivery among childbearing women cannot go unnoticed if Guinea can contribute in achieving target 1 of the Sustainable Development Goal 3 that aims to reduce global maternal mortality ratio to less than 70 per 100,000 live births by 2030. The findings calls for the need to enhance advocacy and educational strategies like focus group discussions, peer teaching, mentor-mentee programmes at both national and community levels for women to encourage health facility delivery. There is also the need to improve maternal healthcare services utilization policies to promote access to health facility delivery by reducing costs and making health facilities available in communities. It is important for future studies to employ qualitative design to provide a deeper understanding of some of the findings in the current study.

\section{Abbreviations}

AIC: Akaike's Information Criterion; aOR: Adjusted odds ratios; Cl: Confidence interval; GDHS: Guinea Demographic and Health Survey; ICC: Intra-Class Correlation; LR Test: Likelihood ratio Test; PSU: Primary Sampling Unit; SSA: Sub-Saharan Africa

\section{Acknowledgements}

The author thanks the MEASURE DHS for granting free access to the original data. 


\section{Author's contributions}

BOA conceived the study, reviewed literature and carried out the analysis. $\mathrm{BOA}$ provided technical support and critically reviewed the manuscript for its intellectual content. BOA had the final responsibility to submit the manuscript for publication. The author read and amended drafts of the paper and approved the final version.

\section{Funding}

None.

\section{Availability of data and materials}

Data for this study is available at: https://dhsprogram.com/data/dataset/ Guinea_Standard-DHS_2018.cfm?flag=0.

\section{Ethics approval and consent to participate}

Ethics approval was not a requirement in this study since secondary data which is available in the public domain was used. More details regarding DHS data and ethical standards are available can be found at: http://goo.gl/ ny8T6X.

\section{Consent for publication}

Not Applicable.

\section{Competing interests}

The author declares no competing interest.

Received: 14 August 2020 Accepted: 2 November 2020 Published online: 09 November 2020

\section{References}

1. Geller SE, Koch AR, Garland CE, MacDonald EJ, Storey F, Lawton B. A global view of severe maternal morbidity: moving beyond maternal mortality. Reprod Health. 2018;15(1):98

2. Goldenberg RL, McClure EM, Saleem S. Improving pregnancy outcomes in low-and middle-income countries. Reprod Health. 2018;15(1):88.

3. Maternal mortality. 2019 [cited May 16, 2020]. Available from: https://www. who.int/news-room/fact-sheets/detail/maternal-mortality.

4. Moyer CA, Dako-Gyeke P, Adanu RM. Facility-based delivery and maternal and early neonatal mortality in sub-Saharan Africa: a regional review of the literature. Afr J Reprod Health. 2013:17(3):30-43.

5. Tura G, Fantahun M, Worku A. The effect of health facility delivery on neonatal mortality: systematic review and meta-analysis. BMC Pregnancy Childbirth. 2013;13(1):18.

6. Maternal health. 2018 [cited May 16, 2020]. Available from: https://www. who.int/maternal-health/en/.

7. Panel AP. Maternal health. Geneva: Investing in the Lifeline of Healthy Societies and Economies Policy Brief, Africa Progress Panel; 2010.

8. Victora CG, Requejo JH, Barros AJD, Berman P, Bhutta Z, Boerma T, et al. Countdown to 2015: a decade of tracking progress for maternal, newborn, and child survival. Lancet. 2016;387(10032):2049-59.

9. Silver KL, Singer PA. SDGs: start with maternal, newborn, and child health cluster. Lancet. 2014;384(9948):1093-4.

10. Kyei-Nimakoh M, Carolan-Olah M, McCann TV. Access barriers to obstetric care at health facilities in sub-Saharan Africa-a systematic review. Systematic Reviews. 2017;6(1):110

11. Geleto A, Chojenta C, Musa A, Loxton D. Barriers to access and utilization of emergency obstetric care at health facilities in sub-Saharan Africa: a systematic review of literature. Systematic Reviews. 2018:7(1):183.

12. Kifle MM, Kesete HF, Gaim HT, Angosom GS, Araya MB. Health facility or home delivery? Factors influencing the choice of delivery place among mothers living in rural communities of Eritrea. J Health Population Nutrition. 2018:37(1):22.

13. Wanjira C, Mwangi M, Mathenge E, Mbugua G. Delivery practices and associated factors among mothers seeking child welfare services in selected health facilities in Nyandarua South District, Kenya. BMC Public Health. 2011; 11(1):360.

14. Darega B, Dida N, Tafese F, Ololo S. Institutional delivery and postnatal care services utilizations in Abuna Gindeberet District, west Shewa, Oromiya region, Central Ethiopia: a community-based cross sectional study. BMC Pregnancy Childbirth. 2016;16(1):149.
15. Kaul S, You W, Boyle KJ. Delivery at home versus delivery at a health care facility-a case study of Bihar, India; 2012.

16. Jafree SR, Zakar R, Mustafa M, Fischer F. Mothers employed in paid work and their predictors for home delivery in Pakistan. BMC Pregnancy Childbirth. 2018;18(1):316.

17. Ministère de la Santé. Plan Stratégique national SRMNIA 2016-2020. In: Santé Mdl, editor. Guinée 2016.

18. Institut National de la Statistique (INS) and ICF. Demographic and Health Survey in Guinea 2018. Conakry, Guinea, and Rockville, Maryland, USA INS and ICF. ; 2018.

19. Brazier E, Fiorentino R, Barry S, Kasse Y, Millimono S. Rethinking how to promote maternity care-seeking: factors associated with institutional. delivery in Guinea. Health Care Women International. 2014;35(7-9):878-95.

20. World atlas. Guinea-Under five mortality rate. 2018.

21. Abubakar S, Adamu D, Hamza R, Galadima JB. Determinants of home delivery among women attending antenatal care in Bagwai town, Kano Nigeria. Afr J Reprod Health. 2017;21(4):73-9.

22. Ashimi AO, Amole TG. Prevalence, reasons and predictors for home births among pregnant women attending antenatal care in Birnin kudu, Northwest Nigeria. Sexual Reproductive Healthcare. 2015;6(3):119-25.

23. Yaya S, Bishwajit G, Gunawardena N. Socioeconomic factors associated with choice of delivery place among mothers: a population-based cross-sectional study in Guinea-Bissau. BMJ Glob Health. 2019:4(2):e001341.

24. Scott NA, Henry EG, Kaiser JL, Mataka K, Rockers PC, Fong RM, et al. Factors affecting home delivery among women living in remote areas of rural Zambia: a cross-sectional, mixed-methods analysis. Int J Women's Health. 2018:10:589.

25. Mrisho M, Schellenberg JA, Mushi AK, Obrist B, Mshinda H, Tanner M, et al. Factors affecting home delivery in rural Tanzania. Tropical Med Int Health. 2007:12(7):862-72

26. Moindi RO, Ngari MM, Nyambati VCS, Mbakaya C. Why mothers still deliver at home: understanding factors associated with home deliveries and cultural practices in rural coastal Kenya, a cross-section study. BMC Public Health. 2015;16(1):114

27. Boah M, Mahama AB, Ayamga EA. They receive antenatal care in health facilities, yet do not deliver there: predictors of health facility delivery by women in rural Ghana. BMC Pregnancy Childbirth. 2018;18(1):125.

28. United Nations Development Program. Human Development Report, Sustainability and equity: a better future for all [On line]. 2011. Available at: httpzllhdr undp org/en/reports/global/hdr201tldownloadl. Accessed 1 Oct 2020. https:/www.dr.undp.org/en/content/human-development-report-2011.

29. United Nations. World population prospects 2019. 2019.

30. WHO. Country cooperation strategy at a glance: Guinea. Geneva: WHO; 2015.

31. National Institute of Statistics and Economic Analysis INSAE and ICF. Demographic and health survey and with multiple indicators (EDSMICS 2014-2015). Rockville, Maryland, USA: : INSEED, MSP et ICF International; 2015

32. Chernet AG, Dumga KT, Cherie KT. Home delivery practices and associated factors in Ethiopia. J Reproduction Infertility. 2019;20(2):102.

33. Devkota B, Maskey J, Pandey AR, Karki D, Godwin P, Gartoulla P, et al. Determinants of home delivery in Nepal-a disaggregated analysis of marginalised and non-marginalised women from the 2016 Nepal demographic and health survey. PLoS One. 2020;15(1):e0228440.

34. Ganle JK, Mahama MS, Maya E, Manu A, Torpey K, Adanu R. Understanding factors influencing home delivery in the context of user-fee abolition in northern Ghana: evidence from 2014 DHS. Int J Health Plann Manag. 2019; 34(2):727-43.

35. Von Elm E, Altman DG, Egger M, Pocock SJ, Gøtzsche PC, Vandenbroucke $J P$, et al. The strengthening the reporting of observational studies in epidemiology (STROBE) statement: guidelines for reporting observational studies. Int J Surg. 2014;12(12):1495-9.

36. Fekadu GA, Ambaw F, Kidanie SA. Facility delivery and postnatal care services use among mothers who attended four or more antenatal care visits in Ethiopia: further analysis of the 2016 demographic and health survey. BMC Pregnancy Childbirth. 2019;19(1):64.

37. Ngowi AF, Kamazima SR, Kibusi S, Gesase A, Bali T. Women's determinant factors for preferred place of delivery in Dodoma region Tanzania: a cross sectional study. Reprod Health. 2017;14(1):112.

38. Belay A, Sendo E. Factors determining choice of delivery place among women of child bearing age in Dega Damot District, north west of Ethiopia: 
a community based cross-sectional study. BMC Pregnancy Childbirth. 2016; 16(1):229.

39. Adedokun ST, Uthman OA. Women who have not utilized health Service for Delivery in Nigeria: who are they and where do they live? BMC Pregnancy Childbirth. 2019;19(1):93.

40. Delamou A, El Ayadi AM, Sidibe S, Delvaux T, Camara BS, Sandouno SD, et al. Effect of Ebola virus disease on maternal and child health services in Guinea: a retrospective observational cohort study. Lancet Glob Health. 2017;5(4):e448-e57.

41. Camara BS, Delamou A, Diro E, Béavogui AH, El Ayadi AM, Sidibé S, et al. Effect of the 2014/2015 Ebola outbreak on reproductive health services in a rural district of Guinea: an ecological study. Trans R Soc Trop Med Hyg 2017;111(1):22-29

42. van de Pas R, Kolie D, Delamou A, Van Damme W. Health workforce development and retention in Guinea: a policy analysis post-Ebola. Hum Resour Health. 2019;17(1):1-12.

43. Shahabuddin ASM, De Brouwere V, Adhikari R, Delamou A, Bardaj A, Delvaux T. Determinants of institutional delivery among young married women in Nepal: evidence from the Nepal demographic and health survey, 2011. BMJ Open. 2017;7(4):e012446.

44. Kitui J, Lewis S, Davey G. Factors influencing place of delivery for women in Kenya: an analysis of the Kenya demographic and health survey, 2008/2009. BMC Pregnancy Childbirth. 2013;13(1):40.

45. Abebe F, Berhane Y, Girma B. Factors associated with home delivery in Bahirdar, Ethiopia: a case control study. BMC Research Notes. 2012;5(1):653

46. Idris SH, Gwarzo UMD, Shehu AU. Determinants of place of delivery among women in a semi-urban settlement in Zaria, northern Nigeria. Annals African Med. 2006;5(2):68-72.

47. Shrestha SK, Banu B, Khanom K, Ali L, Thapa N, Stray-Pedersen B, et al. Changing trends on the place of delivery: why do Nepali women give birth at home? Reprod Health. 2012;9(1):25.

48. Exavery A, Kanté AM, Njozi M, Tani K, Doctor HV, Hingora A, et al. Access to institutional delivery care and reasons for home delivery in three districts of Tanzania. Int J Equity Health. 2014;13(1):48.

49. Wagle RR, Sabroe S, Nielsen BB. Socioeconomic and physical distance to the maternity hospital as predictors for place of delivery: an observation study from Nepal. BMC Pregnancy Childbirth. 2004;4(1):8.

50. Gabrysch S, Cousens S, Cox J, Campbell OMR. The influence of distance and level of care on delivery place in rural Zambia: a study of linked national data in a geographic information system. PLoS Med. 2011;8(1):1-12.

51. Sumankuuro J, Crockett J, Wang S. Factors influencing knowledge and practice of birth preparedness and complication readiness in sub-saharan Africa: a narrative review of cross-sectional studies. Int J Community Med Public Health. 2016;3(12):3297-307.

52. Sarker BK, Rahman M, Rahman T, Hossain J, Reichenbach L, Mitra DK. Reasons for preference of home delivery with traditional birth attendants (TBAs) in rural Bangladesh: a qualitative exploration. Plos one. 2016;11(1):1-19.

53. Huda TM, Chowdhury M, El Arifeen S, Dibley MJ. Individual and community level factors associated with health facility delivery: A cross sectional multilevel analysis in Bangladesh. PloS one. 2019;14(2):1-13.

54. Zamawe COF, Banda M, Dube AN. The impact of a community driven mass media campaign on the utilisation of maternal health care services in rural Malawi. BMC Pregnancy Childbirth. 2016;16(1):21.

55. Asp G, Pettersson KO, Sandberg J, Kabakyenga J, Agardh A. Associations between mass media exposure and birth preparedness among women in southwestern Uganda: a community-based survey. Glob Health Action. 2014;7(1):22904

56. Ganle JK. Why Muslim women in northern Ghana do not use skilled maternal healthcare services at health facilities: a qualitative study. BMC Int Health Hum Rights. 2015;15(1):10.

57. Offenhauer P, Buchalter AR, editors. Women in Islamic societies: a selected review of social scientific literature2005 2005: Federal Research Division, Library of Congress Washington, DC.

58. Izugbara CO, Ezeh AC. Women and high fertility in Islamic northern Nigeria. Stud Fam Plan. 2010;41(3):193-204.

59. Johnson-Hanks J. On the politics and practice of Muslim fertility. Med Anthropol Q. 2006;20(1):12-30

60. Campos CAS, Malta MB, Neves PAR, Lourenço BH, Castro MC, Cardoso MA. Gestational weight gain, nutritional status and blood pressure in pregnant women. Revista de saude publica. 2019;53:57.
61. Patel A, Prakash AA, Das PK, Gupta S, Pusdekar W, Hibberd PL. Maternal anemia and underweight as determinants of pregnancy outcomes: cohort study in eastern rural Maharashtra. India BMJ open. 2018;8(8):e021623.

62. Wado YD, Afework MF, Hindin MJ. Unintended pregnancies and the use of maternal health services in southwestern Ethiopia. BMC Int Health Hum Rights. 2013;13(1):36.

63. Spierling T, Shreffler KM. Tough decisions: exploring Women's decisions following unintended pregnancies. Front Sociol. 2018;3:11.

64. Calvert C, Baisley K, Doyle AM, Maganja K, Changalucha J, Watson-Jones D, et al. Risk factors for unplanned pregnancy among young women in Tanzania. J Fam Plann Reprod Health Care. 2013;39(4):e2-e.

65. Adeniyi OV, Ajayi Al, Moyaki MG, Ter Goon D, Avramovic G, Lambert J. High rate of unplanned pregnancy in the context of integrated family planning and HIV care services in South Africa. BMC Health Serv Res. 2018;18(1):140.

66. Ahinkorah BO, Seidu A-A, Appiah F, Baatiema L, Sambah F, Budu E, et al. What has reproductive health decision-making capacity got to do with unintended pregnancy? Evidence from the 2014 Ghana demographic and health survey. PLoS One 2019;14(10):1-16.

67. Lowe M, Chen D-R, Huang S-L. Social and cultural factors affecting maternal health in rural Gambia: an exploratory qualitative study. PloS one. 2016;11(9):1-16.

68. Nyblade L, Stockton MA, Giger K, Bond V, Ekstrand ML, Mc Lean R, et al. Stigma in health facilities: why it matters and how we can change it. BMC Med. 2019;17(1):25.

69. Smith MS, Lawrence V, Sadler E, Easter A. Barriers to accessing mental health services for women with perinatal mental illness: systematic review and meta-synthesis of qualitative studies in the UK. BMJ Open. 2019;9(1):19.

\section{Publisher's Note}

Springer Nature remains neutral with regard to jurisdictional claims in published maps and institutional affiliations.

Ready to submit your research? Choose BMC and benefit from:

- fast, convenient online submission

- thorough peer review by experienced researchers in your field

- rapid publication on acceptance

- support for research data, including large and complex data types

- gold Open Access which fosters wider collaboration and increased citations

- maximum visibility for your research: over $100 \mathrm{M}$ website views per year

At BMC, research is always in progress.

Learn more biomedcentral.com/submissions 